The International Journal of Social Sciences and Humanities Invention 6(11): 5716-5723, 2019

DOI: 10.18535/ijsshi/v6i11.06

ICV 2015: 45.28

ISSN: 2349-2031

(C) 2019, THEIJSSHI

Research Article

\title{
The impact of customer engagement on service coordination costs in content service: the mediating effect of customer response profitability
}

\author{
Kyeongho Lee ${ }^{1}$, Byoung Chun Ha (PhD) ${ }^{2}$ \\ ${ }^{1}$ Graduate School of Business, Sogang University, Seoul, S. Korea \& m71905@ sogang.ac.kr \\ ${ }^{2}$ Graduate School of Business, Sogang University, Seoul, S. Korea
}

\begin{abstract}
In order to secure the continuous competitiveness of OTT content services such as YouTube and Netflix, content service SCM promoting the production and distribution of digital information materials is becoming increasingly important. However, previous studies on this are scarce. This study examines the causal relationship between customer engagement, customer response profitability, and service coordination costs from the perspective of a YouTuber, a content creation service provider. In particular, it examines the impact of customer response profitability, a quantitative indicator of customer response, on the use of social media that customers feel and on the relationship between customer engagement and service coordination costs. In this study, we surveyed a YouTuber in Korea, a service provider. SPSS 18, AMOS 20, and PROCESS Macro were used for statistical analysis and hypothesis testing. The analysis shows that the degree of customer engagement on the YouTube channel has a positive effect on customer response profitability and service coordination costs, and that customer response profitability negatively affects service coordination costs (the reduction of costs). The relationship between the customer response profitability and the degree of customer engagement could not be confirmed, but the relationship between customer engagement and the service coordination costs was confirmed. With this study, we contribute to the establishment of policies on the value co-creation framework from the service provider's perspective in content service SCM and on whether to invest in social media in content sourcing.
\end{abstract}

Keywords: value co-creation costs, customer response profitability, MCN (multi-channel network), attribute-based theory

\section{Introduction}

In service science, value co-creation with customers based on $\mathrm{s}$ ervice dominant logic remains a significant topic of research on how to actively engage customers in the service delivery proce ss, even after a considerable period of time. This is because the interaction between the service provider and the customer and how and when the various relationships between values, resour ces, competencies and service entities created and exchanged $\mathrm{w}$ ithin the system occur (Vargo \& Lusch, 2004a; Vargo \& Lusch , 2014) determines the vitality of the service provider.

So far, literature research has focused primarily on two main themes. First, the study focused on the development of value co-creation framework with customers and developed literature studies in the process of identifying factors involved in creative activities (Payne, Storbacka, \& Frow, 2008). Second, a study focused on the benefits of co-creation with customers (Heidenreich, Wittkowski, Handrich, \& Falk, 2015) argued that customer engagement is effective in creating value through research on customer satisfaction and customer loyalty with products and services in the value creation process (Mahr, Lievens, \& Blazevic, 2014). However, some specific conclusions about the benefits or costs of customer engagement in service providers still seem to be in progress. Therefore, this study looks at the cost aspect of value cocreation.

Thus, this study focuses on customer engagement and customer response profitability, which are considered to be important in the coordination mechanism, among the variables identified as structural variables in previous studies in order to elucidate the structure related to the preceding variables of service coordination costs.

On the other hand, the content creation service targeted for this study is popular because subscribers and viewers share their experiences with other participants (Chaffey, 2009). Thus, the creation of dialogue through interaction is an important feature of the Internet (Chaffey, Ellis-Chadwick, Mayer, \& Johnston, 2009) and helps to form groups and communities. In particular, for service providers, social network channels benefit from creating value and building relationships through interaction with customers (Michaelidou, Siamagka, \& Christodoulides, 2011). In this regard, this study attempts to verify the mediating effects of customer response profitability on the relationship between customer engagement and service coordination costs.

This study aims to complement the existing customer-centered research through value co-creation research from the service provider's perspective. Because focusing only on the customer's point of view, the customer is limited in their insight into the management factors between customer engagement and performance (Morosan \& DeFranco, 2016), but rather helps service providers manage the boundaries between co-creation complexity and the benefits and costs of co-creation. This is because there is insight into the coordination mechanism (Cui \& Wu, 2016).

In summary, the purpose of this study is to firstly investigate the effects of customer engagement on service coordination 
costs. Second, we will examine the mediating role of customer response profitability variables in the process of customer engagement affecting service coordination costs. The difference between this study and the previous study is to clarify related mechanisms and to explore the value co-creation cost problem based on the mediating role of customer response profitability in the relationship between customer engagement and service coordination cost.

\section{Theoretical background and hypothesis setting}

\section{A. Customer engagement and value co-creation}

Customer engagement has long been important for the successful product and service development (Alam, 2002). Subsequently, research related to the results of the customer experience was presented in the service-related study, and customer engagement was considered important as a coproducer, a strategically important asset (Lengnick-Hall, Claycomb, \& Inks, 2000).

Value co-creation reflects customer engagement, such as interaction and profit growth, and the benefits associated with service providers (Plé \& Chumpitaz Cáceres, 2010). This is a key principle of service dominant logic that focuses on the role of customers actively participating in service provision (Vargo \& Lusch, 2004a). Value co-creation relies heavily on successful integration of operant resources (i.e. skills, knowledge or competence) and operand resources (i.e. tools, equipment or other products) (Lusch \& Nambisan, 2015). Existing research on customer engagement assumes that customers can provide operant resources with diverse knowledge and skills, while companies can provide both operant and operand resources to manage the co-creation process (Vargo \& Lusch, 2004a). In essence, a customer is a collaborator and competitor in a relationship with a service provider (Prahalad \& Ramaswamy, 2000).

This study focuses on optimally engaging customers in new ways to manage customer experience and improve service quality (Lusch \& Nambisan, 2015). In addition, customer engagement was studied as a parameter as well as an independent variable (Carbonell, Rodríguez-Escudero, \& Pujari, 2009). Customers create real value through the process of customer engagement: customer response in social media such as YouTube, Facebook and Twitter. Signals for satisfaction, trust and loyalty that service providers can assess can provide accurate information about perceived relationship quality through online or offline communication. Here, customer engagement in social media activities is an indicator of customer response profitability.

Despite many benefits raised above, value co-creation can be costly to service providers. For example, customer engagement can reduce corporate control because of limited knowledge of new technologies (Plé \& Chumpitaz Cáceres, 2010). In value co-creation, it can lead to repeated iterations of trial and error (Perks, Gruber, \& Edvardsson, 2012) or customer identification and recruitment, and the management of various resources to coordinate customers and internal actors (Wong, Peko, Sundaram, \& Piramuthu, 2016). In addition, duplicate information may be generated or information overload may occur (Bogers, Afuah, \& Bastian, 2010). In addition, there may be a high service coordination cost if a large number of units participate in social media (Provan, 1983). In addition, empirical studies on these negative consequences of customer engagement in the service sector are still limited (Plé \& Chumpitaz Cáceres, 2010).

Therefore, this study shows that customer engagement shows the positive result of the co-creation of value across the organization in the service coordination cost, but the profit dilemma is the cost dilemma in the factor of the service coordination cost. Against this background, the following hypothesis is set.

Hypothesis 1: Customer engagement will have a positive effect on service coordination costs.

Hypothesis 2: Customer response profitability will have a negative impact on service coordination costs.

\section{B. Customer engagement and customer response profitability}

Customer engagement focuses more on why and how customers engage in value co-creation in service literature (Chathoth, Altinay, Harrington, Okumus, \& Chan, 2013). Value co-creation in service literature studies is positively related to high customer engagement and customer satisfaction, trust, employee satisfaction, sales performance and organizational innovation (Morosan \& DeFranco, 2016; Ordanini \& Parasuraman, 2011; Park \& Allen, 2013). These positive outcomes depend on the customer's personal characteristics, corporate support and culture, and employee involvement (Cha, Yi, \& Bagozzi, 2016). On the other hand, customers are more likely to participate in co-creation of service value in experiential services (Jeon, Park, \& Yi, 2016a; Morosan \& DeFranco, 2016).

This study examines the impact of channel investment and customer engagement on the frequency of visits. Here, the impact of customer's social media participation on customer response profitability is quantified through the service provider's perception.

The service provider's perception of service customer satisfaction is related to the customer's perception. This means that service providers can show the indicator of customer response profitability with respect to perceived relationship quality (Rishika, Kumar, Janakiraman, \& Bezawada, 2013). Against this background, the following hypothesis is set.

Hypothesis 3: Customer engagement has a positive effect on customer response profitability.

\section{Mediating effect of customer response profitability}

Customer engagement serves to increase the communication and relationship creation needed to meet the intrinsic value of the customer. This can be seen through customer response into social media, i.e. customer investment. For example, clear criteria such as the number of visits to each application, the time spent in each application, and so on, including active customer investments such as subscribers, views, likes, and comments, all include customer response. Therefore, service providers need to be interested in customer response in social 
Kyeongho Lee et.al / The impact of customer engagement on service coordination costs in content service: the mediating effect of customer response profitability

media. For example,

Instead of emphasizing their own marketing investments and calculating the returns in terms of customer response, managers should begin by considering consumer motivations to use social media and then measure the social media investments customers make as they engage with the marketers' brands (Hoffman \& Fodor, 2010).

On the other hand, previous studies tend to focus only on the direct or indirect relationship between customer engagement and customer response profitability with service coordination costs, and there was no verification of the causality between customer engagement and customer response profitability and service coordination costs. Previous social networking service (SNS) or social media information system studies examined whether using information technology improved business profitability and productivity. Most of the previous studies, however, did not take into account situational or coordination factors that could affect corporate performance and productivity.

However, even if customer engagement promotes the cost of service coordination, the question of whether it will have a positive impact without requiring parameter intervention, or whether it requires intervention of service is a matter of coordinating service in value co-creation. This is a very important question in the cumulative process of exploring the mechanism of costs in all directions.

In this regard, if the profitability of customer response mediates the effect of customer engagement, the cost of service coordination will be further reduced. The basis is as follows.

First, social media use information technology to improve business profitability and productivity. This demonstrates that through intangible service attributes, improved coordination, quality improvement, or diversity increases (Shin, 1999).

Second, social media and online collaboration platforms make it easier and more effective to organize communities (Flanagin \& Metzger, 2000). The Internet is optimized for collaborative decision making, and the optimizations resulting from the connection between content and user data (Linders, 2012) and algorithms can reduce coordination costs (Shin, 1999).

Therefore, this study pays attention to the mediating effect of profitability of customer investment, which is emphasized in attribute-based theory as well as the prediction that it can mediate the relationship between customer engagement and coordination cost in the comprehensive results of the preceding studies. This is because of the coordination mechanism. According to attribute-based theory, coordination mechanisms are a set of methods used to manage interdependencies between organizations in the supply chain. The coordination mechanism links the four attributes - differentiated attributes based on resource sharing structure, decision style, level of control and risk sharing - into each of the following costs: coordination costs, operational risk costs and opportunity costs. This will facilitate associating each coordination mechanism attribute with a kind of cost (Xu \& Beamon, 2006), resulting in a reduction in the coordination cost.

As a result, the more interaction there is in the channels provided by service providers, i.e., the greater the company's performance and productivity through customer response (customer investment) to social media, the lower the likelihood of coordination costs.

Therefore, this study establishes the following hypothesis under the causal relationship between customer engagement $\rightarrow$ customer response profitability $\rightarrow$ service coordination cost.

Hypothesis 4: Customer response profitability will mediate the relationship between customer engagement and service coordination costs.

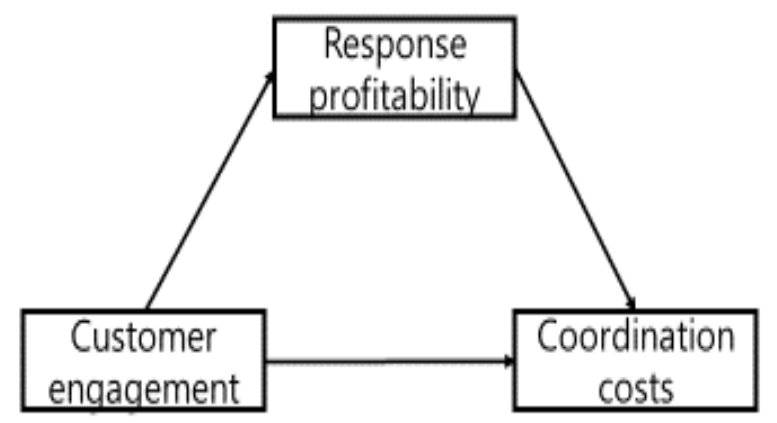

Figure 1. Research model

\section{Empirical research}

\section{A. Data collection and sample characteristics}

This study examines the impact of customer engagement and customer response profitability on service coordination costs, and whether the process identifies the mediating effects of customer response profitability.

For empirical research, we collected surveys through a nonprobability sampling from a YouTuber, a service provider in Korea, and conducted snowball sampling and purpose sampling for a non-probability sampling. Over 1 months, 1401 questionnaires were distributed through e-mail and SNS, and 173 copies of the collected 181 questionnaires were used for the final analysis. The general characteristics of the samples in the study are shown in Table 1.

\section{Table 1. Respondent's characteristics}

\begin{tabular}{c|c|c|c}
\hline \multicolumn{2}{c|}{ class } & frequency & $\%$ \\
\hline \multirow{4}{*}{ gender } & M & 84.0 & 48.6 \\
\cline { 2 - 4 } & $\mathrm{F}$ & 89.0 & 51.4 \\
\hline \multirow{4}{*}{ age } & $10 \mathrm{~s}$ & 29.0 & 16.8 \\
\cline { 2 - 4 } & $20 \mathrm{~s}$ & 83.0 & 48.0 \\
\cline { 2 - 4 } & $30 \mathrm{~s}$ & 43.0 & 24.9 \\
\cline { 2 - 4 } & $40 \mathrm{~s}$ & 120 & 6.9 \\
\hline \multirow{3}{*}{ job type } & over 50s & 6.0 & 3.5 \\
\hline \multirow{2}{*}{$\begin{array}{c}\text { types of } \\
\text { business }\end{array}$} & full-time & 38.0 & 21.9 \\
\cline { 2 - 4 } & part-time & 135.0 & 78.0 \\
\cline { 2 - 4 } & personal & 130.0 & 75.1 \\
\hline \multirow{4}{*}{} & less than 1000 & 43.0 & 24.9 \\
\cline { 2 - 4 } & $\begin{array}{c}1,000 \\
\text { to } 10,000\end{array}$ & 11.0 & 5.1 \\
\hline
\end{tabular}


Kyeongho Lee et.al / The impact of customer engagement on service coordination costs in content service: the mediating effect of customer response profitability

\begin{tabular}{c|c|c|c}
\hline \multirow{4}{*}{ subscribers } & $\begin{array}{c}10,000 \\
\text { to } 100,000\end{array}$ & 63.0 & 29.4 \\
\cline { 2 - 4 } & $\begin{array}{c}100,000 \text { to } 1 \\
\text { Million }\end{array}$ & 38.0 & 17.8 \\
\cline { 2 - 4 } & $\begin{array}{c}\text { Over } \\
1 \text { Million }\end{array}$ & 1.0 & 0.5 \\
\hline Total & \multicolumn{2}{|c|}{173.0} & 100.0 \\
\hline
\end{tabular}

\section{B. Operational definition and measurement tools}

The independent variable in this study is customer engagement, the dependent variable is service coordination cost, and the parameter is customer response profitability. Demographic variables were set as control variables. The level of analysis is at the organizational level, and the questionnaire used the Likert equation 7 -point scale $(1=$ not at all, $4=$ normal, $7=$ very true). The demographic variables included gender, age group, full-time or part-time youtubers, actual years of activity, youtuber type classification based on contents, and the number of channel subscribers were included in the control group.

1) Service coordination costs: Service coordination costs are defined as resources used by service providers to communicate internally with resources used to communicate externally with customers by involving them in the service delivery process. To measure this, several prior studies used the measure 4 item for the cost of coordination and communication with internal and external customers during the process of Kim, Stump, \& Oh, 2009, which has been validated and reliable. The service coordination costs consisted of four questions: subscribers' disputes, complaints, and account suspensions, confusion of complex information caused by customer engagement, dispute settlement between subscribers, and copyright resolution.

2) Customer engagement: Customer engagement is effective in value co-creation (Vargo \& Lusch, 2004b), especially in the form of value co-creation (Ordanini \& Parasuraman, 2011). Measurement tools were measured using three items that reflect the way service providers listen to customers and use customer information during the process of Ordanini \& Parasuraman, 2011, which has been validated and reliable in several previous studies. Customer engagement consisted of three questions: the magnitude of the number of subscribers (viewers) interacting with each other on the channel, the frequency of communication, the degree of normal interaction, and the degree of interaction between subscribers (viewers).

3) Customer response profitability: Customer response profitability, which is the number of visits to each application, including active customer response in social media, such as subscribers, views, likes, comments, etc., time spent in each application, and customer investment (Hoffman \& Fodor, 2010). The specific questionnaire used measurement tools from Hoffman \& Fodor, 2010 and Chang \& Chen, 1998. The profitability of a customer's investment is 5 questions, including the number of subscribers, views, likes, revenue (including advertising and sponsored revenue), and how often the frequency of collaboration (linking) to other channels increases or decreases over the last year of activity.

\section{Validity and reliability of construction concepts}

In order to measure the validity of the measurement tool that indicates whether the main concepts of this study, except demographic variables, are properly measured, the confirmatory factor analysis (CFA) was conducted using AMOS 20. To compare $\chi^{2} / \mathrm{df}$, RMR, NFI, IFI, CFI, RMSEA items. As a result of factor analysis, $\chi^{2}=110.609, \mathrm{df}=51, \mathrm{p}=$ $.000, \mathrm{CMIN} / \mathrm{df}=2.169, \mathrm{RMR}=.193, \mathrm{GFI}=.905, \mathrm{AGFI}=$ $.855, \mathrm{NFI}=.926, \mathrm{IFI}=.964, \mathrm{TLI}=.955, \mathrm{CFI}=.964$, and RMSEA $=.082$, the model's goodness-of-fit index was not very good, but it did not interfere with the analysis. All these results are displayed in Table 2. Here, the standard loadings showing the convergence (convergence) validity were all over 0.5 , and then the average variance extraction value (AVE) and the conceptual reliability $\mathrm{CR}$ value were verified. In addition, the reliability of constructs (CR) also exceeded the reference value of 0.7 , which satisfies the concentration validity.

On the other hand, the discriminant validity test of latent variables shows that the square root of the AVE values of all two latent variables is larger than the correlation coefficients between two latent variables, as shown in Table 2.

\section{Table 2. AVE \& Construct Reliability}

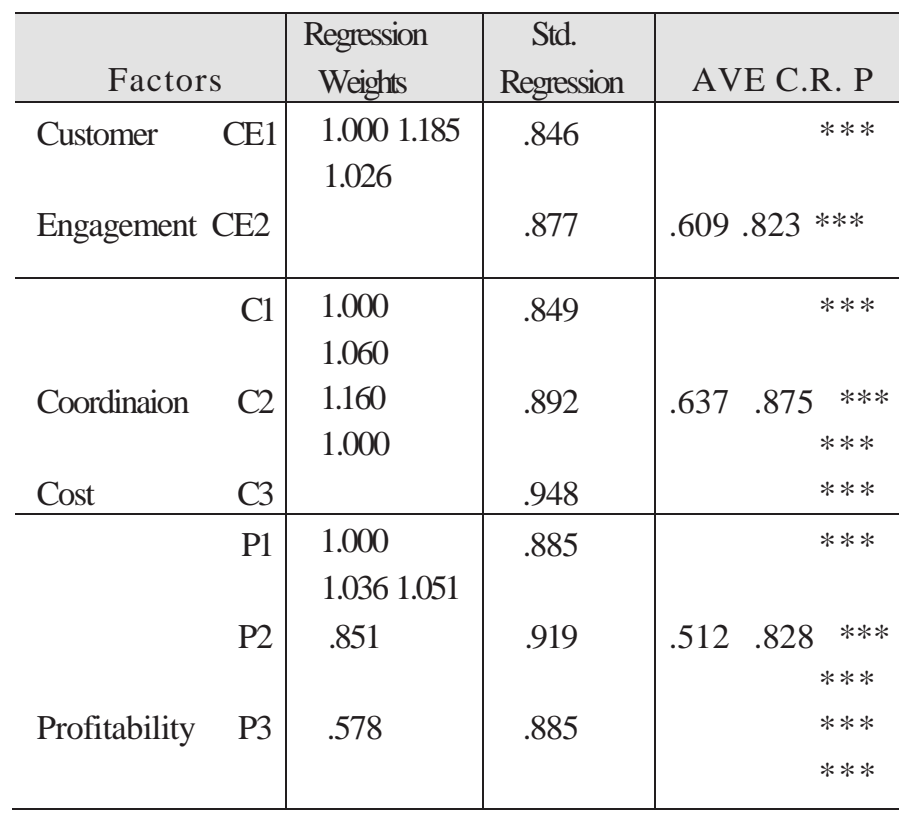

$* * * \mathrm{p}<.001$

Model Fit: $\chi^{2}=110.609, \quad \mathrm{df}=51, \quad \mathrm{p}=.000, \quad \mathrm{CMIN} / \mathrm{df}=2.169$, $\mathrm{RMR}=.193, \mathrm{GFI}=.905, \mathrm{AGFI}=.855, \mathrm{NFI}=.926, \quad \mathrm{IFI}=.964$, $\mathrm{TLI}=.955, \mathrm{CFI}=.964, \mathrm{RMSEA}=.082$

Table 3. Correlations for All Variables

\begin{tabular}{l|c|c|c}
\hline \multicolumn{1}{c|}{ Variables } & $\begin{array}{c}\text { Customer } \\
\text { Engagement }\end{array}$ & $\begin{array}{c}\text { Coordination } \\
\text { Cost }\end{array}$ & Profitability \\
\hline Customer Engagement & $(.6090)$ & & \\
\hline Coordination Cost & 0.1550 & $(.6370)$ & \\
\hline Profitability & 0.5080 & 0.7110 & $(.5120)$ \\
\hline
\end{tabular}

* Number of Diagonal Direction means Root of AVE.

D. Basic Statistics and Correlation Analysis 
Kyeongho Lee et.al / The impact of customer engagement on service coordination costs in content service: the mediating effect of customer response profitability

SPSS 18.0, AMOS 20, and PROCESS Macro were used for statistical analysis and hypothesis testing. As a result of correlation analysis, there was a significant correlation between customer engagement as an independent variable, service coordination cost as a dependent variable, and profitability as a parameter. In addition, a significant correlation was found between profitability, a parameter, and customer engagement, an independent variable.

\section{E. Hypothesis verification through PROCESS Macro}

The PROCESS Macro technique presented by Hayes (2017) can compensate for the defects of Baron \& Kenny's three-step or Sobel test, which is a method of verifying the mediation effects. First of all, Baron \& Kenny's 3rd step is too old and low precision in that it predicts the mediating effect through three-step causal inference, rather than directly verifying the actual mediating effect, and if two or more parameters exist, In the case of offsetting effects between variables, there is a possibility that the mediating effect is absent. In addition, dividing mediating effects into full and partial mediating effects is also considered an unnecessary procedure (Preacher \& Hayes, 2004). In addition, the Sobel Test, which is considered to have a mediating effect when the $\mathrm{Z}$ value is greater than \pm 1.96 and is statistically significant at the significance level of .05, assumes a normal distribution assumption in the significance test, but is actually an interaction* interaction. The mediating effect is often against the normality of distribution (Shrout \& Bolger, 2002). In this respect, PROCESS Macro has the advantage of being able to verify the mediation effects collectively by verifying the direct and indirect effects of independent variables in the leastsquares regression (OLS) analysis.

This study performed hypothesis testing by applying Model $4 \mathrm{o}$ f PROCESS Macro technique. This is because this study model tries to predict the mediating effect of customer response profit ability. The analysis results using Model 4 are shown in Table 4. Model 4 validation included control variables as covariates $b$ ut excluded them as not significant.

1) Validation of hypothesis 1: As a result of analyzing the effec $t$ of customer engagement as an independent variable on the ser vice coordination cost as a dependent variable, the $F$ value was 3.9355 and was significant $(\mathrm{P}<0.05)$. The standardized path co efficient (0.1500) of customer engagement as an independent $\mathrm{v}$ ariable was significant at $\mathrm{p}<0.05$. In addition, the significance of the relationship was confirmed because there was no 0 betw een the minimum coefficient value (LLCI) 0.0007 and the maxi mum coefficient value (ULCI) 0.2992 in the confidence interva 1 as bootstrapping estimates (Shrout \& Bolger, 2002). However , this is the sum of the direct and indirect effects of the total eff ect of customer engagement, an independent variable, on servic e coordination costs, a dependent variable. Meanwhile, in the middle of Table 4, the regression model with both independent and parameter variables showed 0.2631 direct effect on the dep endent variable, which was almost significant at the significanc e level of 0.01 with $\mathrm{p}=0.0017$. This strongly suggests indirect $\mathrm{e}$ ffects through parameters. In conclusion, Hypothesis 1 was ado pted.

2) Validation of hypothesis 2: As a result of analyzing the effect of the parameter customer response profitability (along with the independent variable customer engagement) on the dependent variable service coordination cost, the $F$ value is 6.6968, which is significant, ensuring the model's suitability. The parameterized standardized path coefficient $(-0.2517)$ of customer response profitability was significant below $\mathrm{p}=0.01$. In addition, as the bootstrapping estimate, there was no 0 between the minimum coefficient value (LLCI) -0.4149 and the maximum coefficient value (ULCI) -0.0885 in the confidence interval, the significance of the relationship between variables was confirmed. Thus, Hypothesis 2 was adopted.

3) Validation of hypothesis 3: As a result of analyzing the relationship between the customer engagement as an independent variable and the profitability of the customer as a parameter, the $F$ value was 43.3241 , which was significant at $p$ $<0.001$, thereby ensuring the suitability of the model. The standardized path coefficient (.4496) of customer engagement, an independent variable, was significant below $p=0.0001$. In addition, since there is no 0 between the minimum coefficient value (LLCI) 0.3148 and the maximum coefficient value (ULCI) 0.5844 in the confidence interval as the bootstrapping estimate, the significance of the relationship between variables is confirmed. Hypothesis 3 was also adopted.

Table 4. Simple Mediating Effect by PROCESS Macro (Model 4)

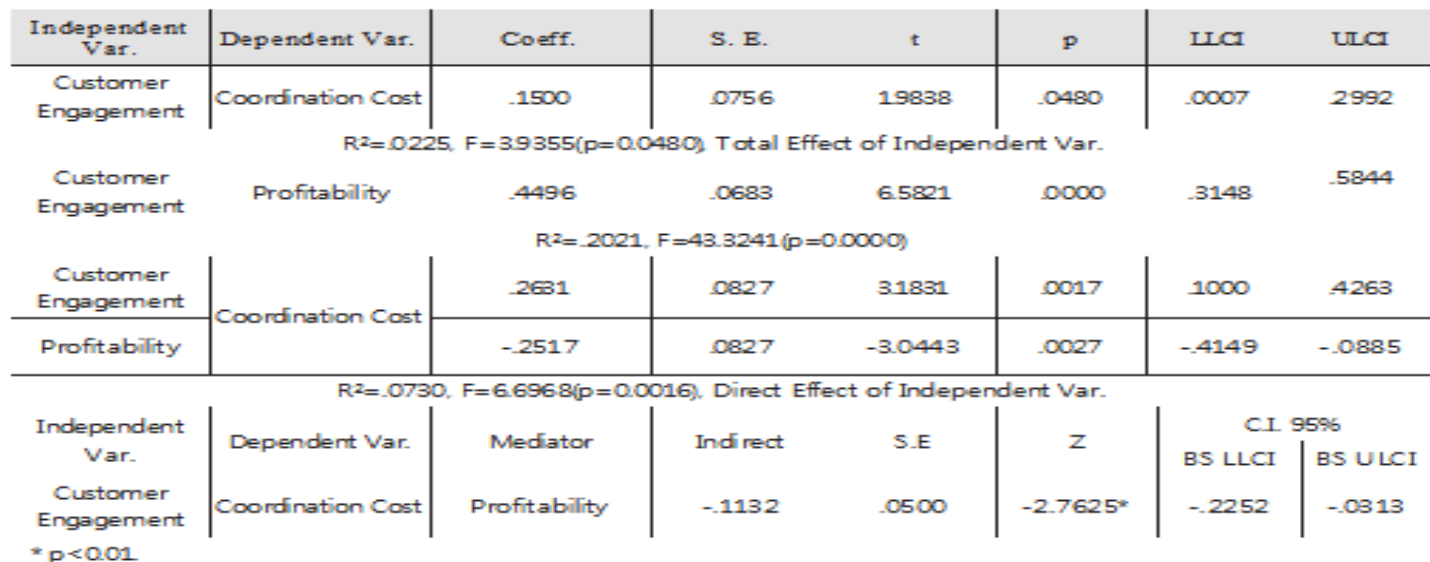


4) Validation of hypothesis 4: Hypothesis 4 is to verify the mediating effect of customer response profitability on the relationship between customer engagement as an independent variable and service coordination cost as a dependent variable. The number of samples extracted by bootstrapping in the analysis was 5,000, and the lower and upper bounds of the indirect coefficient were found in the $95 \%$ confidence interval. As shown in Table 4, the indirect effect of bootstrapping is .1132, and its statistical significance is determined by the presence of zero in the presented confidence interval. In the relationship between customer engagement and service coordination costs, when the profitability of customer response was entered as a parameter, the median effect coefficient lower limit was -0.2252 and the upper limit was -.0313 , which obtained the statistical significance of the indirect effect at the 95\% confidence level. Finally, hypothesis 4 about the mediating effect of profitability of customer response is adopted.

\section{Conclusion and Implications}

\section{A. Theoretical implications}

The purpose of this study is to examine the causal relationship between customer engagement, customer response profitability, and service coordination costs for YouTubers who are active in content creation services in Korea. It is to verify the mediating effect of customer response profitability on the relationship. This study theoretically examined the internal mechanism of service coordination costs in terms of customer engagement and value co-creation costs by demonstrating the preceding factors of service coordination costs.

The theoretical implications of this study are as follows.

First, among the variables affecting service coordination costs related to customer engagement and value co-creation costs, the direct or indirect variables of customer engagement and customer response profitability variables that were not examined or only partially identified in the previous study. Empirical analysis of the effects identified the variables needed to address the cost of value co-creation. More specifically, the study identified the role of customer response profitability parameters in relation to the positive or negative impact of customer engagement and customer response profitability on service coordination costs, as well as the positive or negative impact of customer engagement on service coordination costs. It is important to note that the importance of attribute-based theory is that a coordinating mechanism, i.e. tools for effectively managing these interactions with the knowledge of the participants, entities and processes that interact to execute the objectives, is essential to affect service coordination costs (Xu \& Beamon, 2006).

Secondly, in the methodology, this study has implications for verifying the mediating role of profitability of customer response using the PROCESS Macro of Hayes. In other words, Baron \& Kenny's (1986) verification method and Sobel Test that were commonly used in the past have been overcome. Using the PROCESS Macro analysis presented by Hayes, the magnitude of the direct and indirect effects on the dependent variable of the independent variable could be detected.

Thirdly, as an analysis unit, this study aims to complement the existing customer participation-centered research from the service provider's point of view, whereas most value cocreation studies focus only on the customer's point of view. This is because customers are limited in their insight into management factors that affect the relationship between customer engagement and management performance. Service providers, therefore, have a role to provide insights into internal mechanisms that can help solve the dilemma between benefits and costs in value co-creation studies (Cui \& Wu, 2016).

\section{B. Practical implications}

The practical implications of this study are as follows.

First, it indicates that customer engagement in Korea's content creation service not only creates benefits but also incurs coordination costs. In general, practitioners tend to overemphasize only the benefits of co-creation with customers. However, customer engagement is two-sided, and service providers also suggest that the coordination costs incurred by customer engagement should include internal coordination as well as external coordination with subscribers.

Secondly, customers are generally more likely to participate in co-creation of service value in experiential services (Jeon, Park, \& Yi, 2016b). It is true that customers have much greater control over their social media experience, but service providers also have control over channel rules and operations for social media participation. In addition, service providers cannot control the content of interactions between subscribers, but they can control the creation of rules to encourage interaction between subscribers (Hoffman \& Fodor, 2010). In practice this means that service providers can exercise control and create and manage social media communities.

Thirdly, in the context of intensifying competition between the platform and contents, it is suggested that customer engagement can generate more benefits through the appropriate reduction of coordination costs from the perspective of a service provider who is a YouTuber. The results of this study suggest implications for the growth direction of new industries such as MCN, beyond the legacy system, for efficient operation of service providers in the face of the problems of service adjustment costs due to the emergence of new content distribution platforms and changes in content consumption tendencies.

\section{Limitations and challenges}

This study leaves some limitations and challenges.

First, this study is an empirical study that extracts samples from YouTubers who are active in content creation services in Korea, and has a certain limitation in generalizing the research results. In addition, in this study, non-probability sampling was performed because the population was unknown. As a result, about $25 \%$ of the samples appeared as MCN youtubers, which may not accurately reflect the entire distribution of membership patterns. Therefore, in subsequent studies, it is 
Kyeongho Lee et.al / The impact of customer engagement on service coordination costs in content service: the mediating effect of customer response profitability

necessary to consider allocation sampling or proportional stratification sampling by considering various control variables according to the preceding studies. In addition, empirical research needs to be extended to public sector organizations and social communities where customer engagement and citizen participation are increasingly important in value creation.

Second, this study investigates customer engagement in value co-creation from the perspective of service provider rather than the existing customer. As a result of measuring all dependent independent variables from the same responder, there is a possibility of common method bias that the correlation between the variables used is rather exaggerated. To prevent this, it is necessary to use Harman's one-fact method, which is not a problem. Future research requires multidimensional analysis research design that collects the data in multi-levels with different sources of responses.

Third, this study broadly conceptualized customer engagement, customer response profitability, and service coordination cost variables into a single dimension. In terms of measuring customer engagement, customer response profitability, and service coordination costs, each measurement was made up of three to five items. This is a concept composed of a relatively small number of items, which can impair concept validity. In practice, each variable requires a multidimensional structure of items that measures internal resources as well as external resources (Fang, 2008).

Fourth, this study dealt with service coordination costs in terms of value co-creation costs, but more research using service coordination costs as a dependent variable is needed to obtain practical implications. The focus here is on what happened after the customer was involved in the service delivery process, but future research will examine the factors that influence value co-creation activities with the customer and encourage them to participate from the customer's point of view in the service delivery process. There is a need to investigate previous studies.

\section{References}

[1] Alam, I. (2002). An exploratory investigation of user involvement in new service development. Journal of the Academy of Marketing Science, 30(3), 250.

[2] Bogers, M., Afuah, A., \& Bastian, B. (2010). Users as innovators: A review, critique, and future research directions. Journal of Management, 36(4), 857-875.

[3] Carbonell, P., Rodríguez-Escudero, A. I., \& Pujari, D. (2009). Customer involvement in new service development: An examination of antecedents and outcomes. Journal of Product Innovation Management, 26(5), 536-550.

[4] Cha, M., Yi, Y., \& Bagozzi, R. P. (2016). Effects of customer participation in corporate social responsibility (CSR) programs on the CSR-brand fit and brand loyalty. Cornell Hospitality Quarterly, 57(3), 235-249.

[5] Chaffey, D. (2009). E-business and E-commerce management, strategy, implementation \& practice, prentice hall, 2009: E-business and E-commerce management, strategy, implementation \& practice Bukupedia.

[6] Chaffey, D., Ellis-Chadwick, F., Mayer, R., \& Johnston, K. (2009). Internet marketing: Strategy, implementation and practice Pearson Education.

[7] Chathoth, P., Altinay, L., Harrington, R. J., Okumus, F., \& Chan, E. S. (2013). Co-production versus co-creation: A process based continuum in the hotel service context. International Journal of Hospitality Management, 32, 1120.

[8] Cui, A. S., \& Wu, F. (2016). Utilizing customer knowledge in innovation: Antecedents and impact of customer involvement on new product performance. Journal of the Academy of Marketing Science, 44(4), 516538.

[9] Fang, E. (2008). Customer participation and the trade-off between new product innovativeness and speed to market. Journal of Marketing, 72(4), 90-104.

[10] Flanagin, A. J., \& Metzger, M. J. (2000). Perceptions of internet information credibility. Journalism \& Mass Communication Quarterly, 77(3), 515-540.

[11] Heidenreich, S., Wittkowski, K., Handrich, M., \& Falk, T. (2015). The dark side of customer co-creation: Exploring the consequences of failed co-created services. Journal of the Academy of Marketing Science, 43(3), 279-296.

[12] Hoffman, D. L., \& Fodor, M. (2010). Can you measure the ROI of your social media marketing? MIT Sloan Management Review, 52(1), 41.

[13] Jeon, S., Park, C., \& Yi, Y. (2016a). Co-creation of background music: A key to innovating coffee shop management. International Journal of Hospitality Management, 58, 56-65.

[14] Jeon, S., Park, C., \& Yi, Y. (2016b). Co-creation of background music: A key to innovating coffee shop management. International Journal of Hospitality Management, 58, 56-65.

[15] Lengnick-Hall, C. A., Claycomb, V., \& Inks, L. W. (2000). From recipient to contributor: Examining customer roles and experienced outcomes. European Journal of Marketing, 34(3/4), 359-383.

[16] Linders, D. (2012). From e-government to wegovernment: Defining a typology for citizen coproduction in the age of social media. Government Information Quarterly, 29(4), 446-454.

[17] Lusch, R. F., \& Nambisan, S. (2015). Service innovation: A service-dominant logic perspective. MIS Quarterly, 39(1)

[18] Mahr, D., Lievens, A., \& Blazevic, V. (2014). The value of customer cocreated knowledge during the innovation process. Journal of Product Innovation Management, 31(3), 599-615.

[19] Michaelidou, N., Siamagka, N. T., \& Christodoulides, G. (2011). Usage, barriers and measurement of social media marketing: An exploratory investigation of small and medium B2B brands. Industrial Marketing Management, 40(7), 1153-1159. 
Kyeongho Lee et.al / The impact of customer engagement on service coordination costs in content service: the mediating effect of customer response profitability

[20] Morosan, C., \& DeFranco, A. (2016). Co-creating value in hotels using mobile devices: A conceptual model with empirical validation. International Journal of Hospitality Management, 52, 131-142.

[21] Ordanini, A., \& Parasuraman, A. (2011). Service innovation viewed through a service-dominant logic lens: A conceptual framework and empirical analysis. Journal of Service Research, 14(1), 3-23.

[22] Park, S., \& Allen, J. P. (2013). Responding to online reviews: Problem solving and engagement in hotels. Cornell Hospitality Quarterly, 54(1), 64-73.

[23] Payne, A. F., Storbacka, K., \& Frow, P. (2008). Managing the co-creation of value. Journal of the Academy of Marketing Science, 36(1), 83-96.

[24] Perks, H., Gruber, T., \& Edvardsson, B. (2012). Cocreation in radical service innovation: A systematic analysis of microlevel processes. Journal of Product Innovation Management, 29(6), 935-951.

[25] Plé, L., \& Chumpitaz Cáceres, R. (2010). Not always cocreation: Introducing interactional co-destruction of value in service-dominant logic. Journal of Services Marketing, 24(6), 430-437.

[26] Prahalad, C. K., \& Ramaswamy, V. (2000). Co-opting customer competence. Harvard Business Review, 78(1), 79-90.

[27] Preacher, K. J., \& Hayes, A. F. (2004). SPSS and SAS procedures for estimating indirect effects in simple mediation models. Behavior Research Methods, Instruments, \& Computers, 36(4), 717-731.

[28] Provan, K. G. (1983). The federation as an interorganizational linkage network. Academy of Management Review, 8(1), 79-89.

[29] Rishika, R., Kumar, A., Janakiraman, R., \& Bezawada, R. (2013). The effect of customers' social media participation on customer visit frequency and profitability: An empirical investigation. Information Systems Research, 24(1), 108-127.

[30] Shin, N. (1999). Does information technology improve coordination? an empirical analysis. Logistics Information Management, 12(1/2), 138-144.

[31] Shrout, P. E., \& Bolger, N. (2002). Mediation in experimental and nonexperimental studies: New procedures and recommendations. Psychological Methods, 7(4), 422.

[32] Vargo, S. L., \& Lusch, R. F. (2004a). Evolving to a new dominant logic for marketing. Journal of Marketing, 68, 1-17.

[33] Vargo, S. L., \& Lusch, R. F. (2004b). Evolving to a new dominant logic for marketing. Journal of Marketing, 68, 1-17.

[34] Vargo, S. L., \& Lusch, R. F. (2014). Evolving to a new dominant logic for marketing. The service-dominant logic of marketing (pp. 21-46) Routledge.

[35] Wong, T. Y., Peko, G., Sundaram, D., \& Piramuthu, S. (2016). Mobile environments and innovation co-creation processes \& ecosystems. Information \& Management, 53(3), 336-344.
[36] Xu, L., \& Beamon, B. M. (2006). Supply chain coordination and cooperation mechanisms: An attributebased approach. Journal of Supply Chain Management, 42(1), 4-12. 